\title{
Mapas de crime: vigilância distribuída e participação na cibercultura
}

\section{Fernanda Bruno}

\section{Resumo}

No âmbito do impulso participativo na

cibercultura, os indivíduos vêm sendo incitados

a participar não apenas das formas de

entretenimento e da produção de bens e serviços que utilizam, como também das práticas de vigilância. Este artigo identifica e problematiza as relações entre participação e vigilância na cibercultura a partir da noção de vigilância distribuída, focalizando os recentes mapas de crime disponibilizados na Internet.

Palavras-chave

Vigilância. Participação. Mapas de crime. Cibercultura.
Fernanda Bruno | bruno.fernanda@gmail.com

Doutora em Comunicação e Cultura pela Universidade Federal do Rio de Janeiro - UFRJ. Professora do Programa de Pós-Graduação em Comunicação e Cultura da UFRJ.

\section{Introdução}

Digite 0 endereço de sua residência ou de qualquer localidade e em segundos visualize um mapa com os crimes ocorridos perto de você. As informações são vastas. Estão disponíveis o tipo de crime, o local, a data e o horário. Se houver interesse, dados do criminoso também estão disponíveis: seu nome, idade, raça, peso, crimes registrados, endereço provável e, em alguns casos, sua fotografia. Para ir adiante, é preciso se cadastrar e pagar: por uma bagatela de dólares pode-se obter um histórico do criminoso incluindo dados sobre seus bens, moradias, parentes etc.

Esse mapa de crimes e criminosos está disponível no site CriminalSearches ${ }^{1}$. Tal gênero de mapa vem se multiplicando na Internet e constitui uma das faces da vigilância distribuída contemporânea.

No âmbito geral, designo por vigilância a atividade de observação sistemática e focalizada de indivíduos, populações ou informações relativos a eles, tendo em vista extrair 


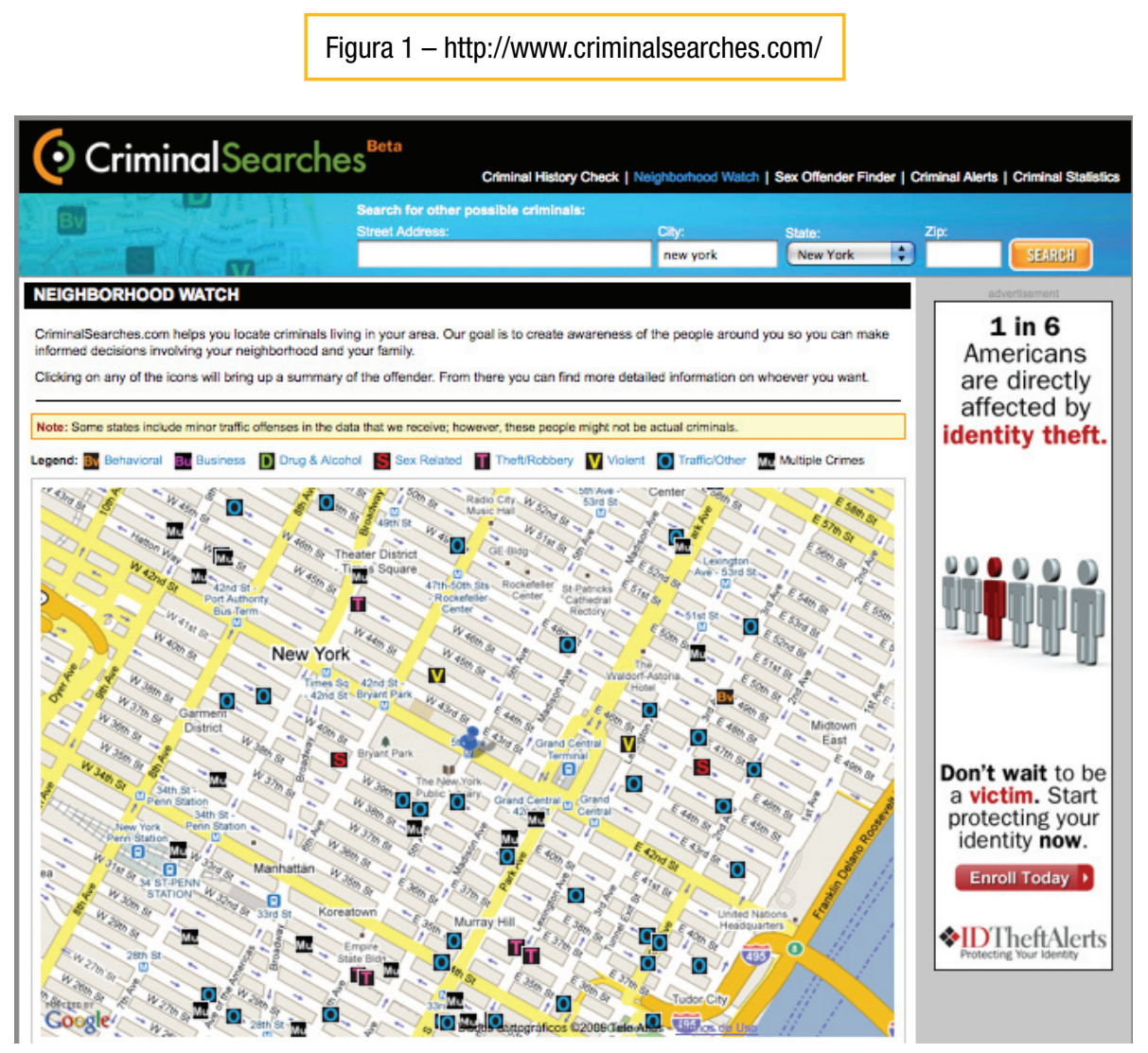

conhecimento e intervir sobre os mesmos, de modo a governar suas condutas ou subjetividades. Esta definição geral precisa, contudo, ser complementada por uma definição contextual da vigilância, atenta às contingências da atualidade.

Proponho o termo vigilância distribuída como definição do estado geral da vigilância nas sociedades contemporâneas. Em linhas breves, trata-se de uma vigilância que tende a se tornar incorporada a diversos dispositivos, serviços e ambientes que usamos cotidianamente, mas que se exerce de modo descentralizado, não hierárquico e com uma diversidade de propósitos, funções e significações nos mais diferentes setores: nas medidas de segurança e circulação de pessoas, informações e bens; nas estratégias de consumo e marketing; nas formas de comunicação, entretenimento e sociabilidade; na prestação de serviços etc. Nota-se que em certos casos ela se exerce misturada a dispositivos que não são prioritariamente voltados para a vigilância, sendo assim uma função potencial ou um efeito secundário de dispositivos que são projetados inicialmente para outras finalidades - comunicação, publicidade, geolocalização etc. Daí deriva uma multiplicidade de objetos atuais ou potenciais da vigilância, que não mais se restringem nem se justificam por grupos 
suspeitos ou supostamente perigosos, mas que podem ser todos e qualquer um - consumidores, transeuntes, internautas, criminosos, participantes de reality shows etc. No seio dessa vigilância "para todos", há uma variedade de focos possíveis, pois não se vigiam ou monitoram apenas indivíduos ou grupos, mas informações, transações eletrônicas, comportamentos, hábitos e rastros no ciberespaço, comunicações, fluxos de corpos anônimos no espaço urbano etc. Não são menos diversos os afetos e as significações subjetivas e sociais que a vigilância hoje mobiliza: se por um lado ela se justifica ou se exerce pelo medo e promessa de segurança e proteção, ela também proporciona diversão, prazer e sociabilidade - como mostram cotidianamente os reality shows, os sites de compartilhamento de imagem, os micro-blogs, as redes sociais etc. Vigora, por fim, um tríplice regime de legitimação da vigilância distribuída: 0 da segurança, 0 da visibilidade midiática (marcado pela presença dos dispositivos de vigilância nos circuitos de entretenimento, sociabilidade e espetáculo) e 0 da eficiência, sobretudo no campo dos serviços das redes e tecnologias de comunicação.

Esta noção, apresentada em seus traços mais gerais, pretende designar um fenômeno bastante complexo e contestar um diagnóstico corrente nos estudos de vigilância (KOSKELA, 2003; GANDY, 1993; POSTER, 1990), nos meios de comunicação e no senso comum. Qual seja, a percepção de um aumento expressivo dos dispositivos de vigilância e na sua caracterização como uma ampliação do sistema panóptico (BENTHAN, 1787), ou do fantasma do Big Brother (ORWELL, 2003).

Pelas características mencionadas, nota-se $\log 0$ que a vigilância distribuída não se confunde com uma vigilância hiper-panóptica, a qual supõe sistemas centralizados, hierarquizados, dirigidos a grupos ou indivíduos previamente delimitados cujas identidades supostamente portam uma periculosidade que demanda vigilância e se inscreve num projeto de normalização. Ainda que aspectos desses sistemas persistam hoje, a vigilância contemporânea se complexificou em relação aos modelos modernos, ganhando novos sentidos, modos de atuação, efeitos.

A noção de distribuição busca designar um processo amplo e espraiado, mas descentralizado, sem hierarquias estáveis e multifacetado, pleno de ambiguidades. 0 adjetivo distribuído ressalta, ainda, uma tensão que provém do seu uso na qualificação de formas atuais de comunicação, sobretudo no ciberespaço e suas redes e ambientes recentes em que vigem a interação e a participação dos usuários. Os territórios moventes da comunicação distribuída (ANTOUN, 2008) se confundem com os da vigilância distribuída, ou melhor, esta última é imanente à primeira e está incorporada a suas engrenagens e critérios de funcionamento e eficiência. Não há, por exemplo, redes sociais (Myspace, Facebook, Orkut) com suas práticas de sociabilidade isentas de qualquer forma de vigilância ou 
monitoramento, e um aparato de vigilância adicional que se apropriaria delas. Ao contrário, os sistemas de vigilância e monitoramento são imanentes a tais redes e são parte integrante tanto da eficiência do sistema, que monitora, arquiva e analisa os dados disponibilizados pelos usuários de modo a otimizar seus serviços, quanto das relações sociais que aí se travam, as quais encontram um de seus motores na vigilância mútua e consentida, com pitadas de voyeurismo e exibicionismo. Do mesmo modo, não existem os sistemas de busca (Google, Yahoo) com sua maquinaria estritamente informacional e uma função exterior de vigilância que se infiltrara neles, desviando seus propósitos iniciais. 0 monitoramento das informações e ações dos indivíduos no ciberespaço é intrínseco a qualquer motor de busca, fazendo parte do seu funcionamento e eficiência.

Além disso, aí reside a tensão a que me referi, a noção e a experiência de distribuição em ambientes e redes comunicacionais, aliadas aos movimentos que caracterizam o que se convencionou chamar de web 2.0 (que em linhas gerais designa os serviços e ambientes na Internet cujo conteúdo é produzido com a participação dos usuários), são ao mesmo tempo uma dimensão potencial de resistência às práticas de vigilância e controle, e uma fonte profícua de dados e conhecimento que nutrem essas mesmas práticas, sobretudo as da vigilância digital (BRUNO, 2008). Ademais, vemos crescer o impulso participativo não apenas na produção de bens, serviços e entretenimento na Internet, mas também no exercício de vigilância, que vem sendo atrelada, nesse contexto, à cidadania. $\mathrm{Ou}$ melhor, em alguns casos a produção de conteúdo está associada ao posicionamento do produtorusuário como vigilante. 0 s mapas de crime se inserem precisamente nesses casos, cruzando a vigilância e a comunicação distribuídas. Problematizarei, nesse contexto, o modo como os indivíduos são mobilizados a adotarem, como parte do seu espírito e prática cidadãos, um olhar e uma atenção vigilantes sobre 0 outro, a cidade e o mundo. Num mesmo movimento, explorarei brevemente limites e potencialidades das relações entre vigilância distribuída e participação na cibercultura, sempre no âmbito dos mapas on-line de crime.

\section{Cartografia e vigilância}

As relações entre cartografia e vigilância são tão antigas quanto diversas. Quanto à visualidade, os mapas (na tradição das Imago Mundi) inscrevem uma perspectiva de sobrevoo, cara ao olhar vigilante e suas figuras míticas ou históricas. Olho de Deus, Ícaro, pássaro, esta visão cartográfica é suficientemente distante e alta para abarcar uma 'totalidade' qualquer, sendo, nesse sentido, 'pan-optica' por excelência. Revisto ou tornado visível no mapa, o mundo se oferece com paisagem e a invisibilidade do todo se inscreve na visibilidade do plano. Ao mesmo tempo, a projeção cartográfica, tal como se firmou no plano bidimensional e geometrizado a 
partir do século XVI (BUCI-GLUKSMAN, 1996), simula uma perspectiva apreendida ao mesmo tempo de todos os ângulos e de lugar nenhum. A projeção cartográfica suprime todo ponto de vista particular, representando uma ordem supostamente 'neutra', segundo a qual o mundosuperfície se oferece como um objeto estável de conhecimento, supervisão, controle e domínio.

Não por acaso, essa perspectiva cartográfica envolve a um só tempo a estética e a ciência, sendo uma das 'imagens' da razão científica moderna e sua ordem representacional. Em tal ordem, a visão-ideia clara e distinta do mundo é tributária de um olho cognoscente que se coloca à distância e em sobrevoo (MERLEAU-PONTY, 1994). A verdade do mundo só é visível pela representação, mais clara no plano cartográfico do que nas dobras e confusões do corpo a corpo com o mundo, como nos mostram o Astrônomo e 0 Geógrafo de Vermeer. Nos dois quadros, o mundo exterior se re-apresenta para o olhar atento e absorto do cientista na forma de um mapa, no primeiro caso, e de um globo terrestre, no segundo.

O olho que sobrevoa e conhece é também 0 olho que exerce poder, controle e vigilância de territórios. Os mapas são decisivos na demarcação e materialização de fronteiras, instituindo territórios e permitindo visualizar e inspecionar propriedades e populações: a cartografia-cadastro é uma tecnologia privilegiada das diversas formas de governo e constituição dos estados, regulando seus processos internos.
0 elo entre 0 ato de vigiar e a produção de mapas é particularmente explícito na etimologia da palavra inglesa survey, proveniente do latim supervidere (super-visão) e que a partir do século XVI significa também 0 ato de produzir mapas (SHORT, 2003 apud LEMOS, 2008). Hoje, o verbo survey significa tanto olhar, examinar atentamente algo, quanto mapear, determinar a forma, posição ou extensão de um pedaço de terra, fazer levantamento topográfico ou pesquisar, visualizar, examinar, coletar sistematicamente dados e/ou opiniões. Na forma substantiva, designa tanto pesquisa, enquete, quanto plano de medida ou descrição topográfica. Como se pode notar, a "surper-visão" do mapa implica um tipo de olhar que vai do menor ao maior, apreendendo seja o detalhe, seja a vastidão dos territórios, seus aspectos e processos que se oferecem não só como objetos de visão, mas de exame e conhecimento.

Quanto aos espaços urbanos, as relações entre mapa e vigilância ficam ainda mais estreitas a partir do século XVIII, quando se constroem mapas cada vez detalhados para a inspeção, controle e previsão de processos urbanos. No século XIX, a técnica cartográfica, a estatística e as ciências humanas e sociais se articulam para mapear processos sociais, biossociais, econômicos, políticos etc. Nos Estados Unidos, a primeira dessas radiografias sociais é 0 Statistical Atlas, de Francis Walker, em 1874, com 44 mapas com dados sobre imigração, etnia, religião, tendências econômicas, densidade populacional: 
"Walker was writing at the same time when social science, social control, and social surveillance were all emerging as important new discourses of a nation experiencing rapid urbanization and large-scale immigration." (SHORT, 2003, p. 164).

Ainda no século XIX, mapas de doenças e crimes são produzidos, constituindo uma cartografia das mazelas e dos perigos sociais que se amplia no século XX. 0 primeiro mapa de crime data de 1829, na França: “...when Balbi and Guerry used data from 1825 to 1827 to plot, for each of the departments in the country, the incidence of crime in relation to educational instruction" (SHORT, 2003, p. 194). Tais mapas expressam "estatísticas morais", termo cunhado pelo próprio Guerry, indicando níveis de crime e pobreza, entre outros fenômenos sociais (Idem).

Tais estatísticas morais se multiplicam hoje segundo formatos sofisticados e renovados, cruzando imensas e variadas bases de dados, constituindo perfis de crimes e criminosos que levam em conta múltiplos fatores (educacionais, biométricos, econômicos, psicológicos, comportamentais etc) que se cruzam com dados geoespaciais. As novas tecnologias de geolocalização (GIS, GPS), juntamente com as redes de comunicação sem fio, contribuem para o incremento de uma "geovigilância", definida como "a mode of surveillance concerned with locations and distributions across spatial territories"(CRAMPTON, 2003, p. 137). Seus propósitos geopolíticos, militares, comerciais, ecológicos são diversos e os mapas on-line de crime são um caso bastante específico dessa geovigilância. Comparados às cartografias morais dos séculos XIX e XX, tais mapas pertencem à mesma linhagem, mas trazem diferenças significativas que expressam o estado da vigilância distribuída na cultura contemporânea, especialmente a sua face participativa.

\section{Mapas de crime: participe e encontre um crime ou criminoso perto de você}

Há não mais que 5 ou 6 anos, aproximadamente, assistimos a uma espécie de explosão cartográfica no ciberespaço. A disponibilização de ferramentas de composição de mapas com interfaces "amigáveis" permitiram que qualquer indivíduo com acesso a Internet possa desenvolver mapas sem nenhuma formação, expertise ou saber específicos para tanto. A cartografia passa ao domínio comum e ordinário, seguindo a velocidade e diversidade do ritmo participativo da web 2.0, visíveis nos inúmeros tipos de mapas que surgem a cada dia na Internet. Do ponto de vista tecnológico, essa explosão cartográfica se deve à popularização de dois dispositivos centrais: os sistemas de informação geográfica (GIS), que permitem capturar, controlar e analisar informações geograficamente referenciadas, bem como visualizá-las em formatos diversos, como mapas, globos, gráficos; e os serviços de visualização e elaboração de mapas on-line. Nesse campo, o Google Maps API foi decisivo, permitindo ao 
usuário manipular mapas on-line com a inserção de seus próprios dados georeferenciados em variados formatos, criando mapas personalizados que podem ser disponibilizados em qualquer sítio eletrônico. Mapas políticos, sociais, artísticos, lúdicos, pessoais, afetivos, entre outros, surgem por toda parte na rede. Os aspectos sociais, cognitivos, sensoriais e estéticos dessa nova forma de mapeamento, a qual propõese chamar "cibercartografia" (TAYLOR; CAQUARD, 2006), são múltiplos e mereceriam um artigo inteiramente dedicado a eles. Limitome à análise dos mapas de crime em sua relação com a vigilância contemporânea.

Tal como grande parte dos mapas no ciberespaço, os mapas de crime são elaborados por indivíduos comuns e não por experts em cartografia, vigilância ou segurança pública. Uma minoria é produzida por algum departamento de polícia, mas quase todos derivam da apropriação de dados públicos por indivíduos ou grupos que não são vinculados a instâncias de governo, conhecimento ou gestão de informações sobre crimes.
Mas o que se vê nesses mapas? No nível elementar, eles permitem visualizar crimes em localidades, com variações no tipo de informação disponibilizada. Há os "especializados" em crimes particulares, como assassinatos (Boston Crime ${ }^{2}$ ), abuso sexual (Sex offenders register'; Map sex offenders ${ }^{4}$ ), enquanto outros são mais amplos e abarcam diversos tipos de crime. Quanto às informações, a maioria fornece os tipos de crime (roubo, assassinato, vandalismo etc), local, data e hora. Outros dão mais detalhes, informando, por exemplo, se houve prisão ou, no caso de roubo, a quantia roubada. Há ainda aqueles que abrem espaços para relatos mais livres da ocorrência (Citix ${ }^{5}$ ) e os que oferecem detalhes sobre os criminosos (Criminal Searches ${ }^{6}$; Family Watchdog ${ }^{7}$ ) ou as vítimas (Los Angeles Times Homicide $\operatorname{maps}^{8}$ ).

Todos os mapas oferecem vias de busca diferenciadas, com mais ou menos opções. Na maioria dos casos, o usuário pode realizar a busca por endereço, data, tipo de crime, ou pela combinação destes fatores. Em alguns, a busca pode ser feita a partir do nome do criminoso ou suspeito. Como se pode notar, pretende-se 
oferecer uma visualização personalizada dos crimes e/ou criminosos que podem estar perto de você. Providos desses mapas, a cidade, seus crimes e criminosos se tornam visíveis a "todos" e os indivíduos podem monitorar as áreas por onde transitam e fazer escolhas de trajetos mais seguros, moradia, investimento etc.

Não é difícil perceber porque tanto a elaboração quanto a utilização desses mapas expressam e constituem uma das faces da vigilância distribuída contemporânea. 0 olhar vigilante e o monitoramento de crimes e criminosos não estão restritos a instituições de inspeção ou segurança, mas a todo indivíduo com acesso à Internet. A distribuição da vigilância vai de par com a incitação à participação. As sessões de descrição dos mapas costumam clamar pelo acesso dos indivíduos aos dados criminais.

The goal is to create an open source crime mapping, reporting, and alert system for the community, so that citizens might have a greater awareness about the safety of their neighborhoods. Any neighborhood organization which wishes to use this system may host it on their own Web site, or on a Web site hosted for them (New Orleans CitizenCrimeWatch.org ${ }^{9}$ ).

A vigilância figura aí como uma atividade ou estado atencional que deve ser 'partilhada' por todos de forma descentralizada. Ao mesmo tempo, deve servir ao uso personalizado. A vigilância participativa é ao mesmo tempo para todos, por todos e para cada um, posto que condensa num só mapa dados de uma totalidade e múltiplas entradas para usos particulares. Em princípio, todo mapa goza dessa característica, mas 0 suporte digital e as interfaces interativas potencializam a apropriação particularizada. 0 seu aspecto visual, inclusive, é parcelado, pois o usuário visualiza a cada vez o seu recorte pessoal na totalidade dos dados, diferentemente dos mapas convencionais que dispõem na superfície uma totalidade que se faz visível num só golpe de olhar.

0 caráter distribuído e particularizado dos mapas de crime também se apresenta - à diferença dos mapas morais da modernidade na 'paisagem' criminal visualizada. Nos mapas modernos, tratava-se de estabelecer relações estatísticas entre processos sociais (educação, faixa de renda) e a incidência de crimes em certas regiões. Tratava-se de radiografias sociais atreladas à produção de conhecimento e ao planejamento de intervenções públicas em larga escala. Diferentemente, os mapas online de crime visam "empoderar" os indivíduos na garantia privatizada de sua segurança, oferecendo a eles uma paisagem cartográfica que não está preocupada com o conhecimento das grandes cadeias causais do crime, nem mesmo com a sua transformação. Trata-se, antes, de informar ocorrências e dados, de modo a permitir o uso preventivo pessoal.

I can't exactly go out and stop any of this crime myself, but where I can help is in putting this 
site together to make people aware of what's going on around them...If you know what crimes have happened in the past, you're probably less likely to be a victim of future crime $\left(\right.$ CrimeinDC.org $\left.{ }^{10}\right)$.

Atualizam-se aí parte das significações atuais da segurança e do risco. Numa cultura do risco ubíquo e generalizado, da falência das teorias que explicavam o crime a partir de causas sociais que seriam sanadas por vastas intervenções públicas (GARLAND, 2001; VAZ, 2006), ampliase a responsabilidade de cada um com sua segurança pessoal, instituindo uma cultura "do-it-yourself surveillance" (ANDREJEVIC, 2007). Contudo, a ausência de uma teria social do crime não impede que tais mapas produzam efeitos e "visões" que reforçam, intencionalmente ou não, certas perspectivas frente ao crime e à violência nas cidades. Muitos deles reiteram uma geografia do crime e das desigualdades sociais em que habitantes de certas regiões ficam sujeitos ao medo, à suspeita e à criminalização indiscriminada.

A vigilância participativa de uso preventivo e pessoal é incrementada pelos Alertas e Feeds, serviços oferecidos por alguns mapas e que consistem no envio de notificações sobre crimes ou criminosos aos usuários, nas áreas por estes escolhidas.

Do you have any registered offenders near you today? No? Great. But could they move in tomorrow? Sure. How will you know? Let us tell you when an offender moves in or out of your area! (Family Watchdog).

0 serviço de alerta, por vezes, nos convida ainda a solicitar informações sobre pessoas de quem podemos ou devemos suspeitar, oferecendo, inclusive, uma lista de 'sugestões': "babás, vizinhos, empregados domésticos, professores, eletricistas, bombeiros, amigos dos seus filhos" (CriminalSearches). Basta enviar o nome completo do "suspeito" e pagar alguns dólares para receber relatórios isolados ou regulares de seu histórico criminal e outras atividades relevantes. Vigilância e suspeita são aí tratadas como elementos corriqueiros e cotidianos nas relações sociais, reiterando o princípio de que todos são suspeitos até que se prove o contrário.

Em certos casos, especialmente nos mapas que expõem dados sobre os criminosos, conjugase 0 estado de suspeição generalizada com a exposição punitiva. Esta de modo algum é inédita e remonta a antigos rituais de punição em que a exposição pública do corpo do condenado é essencial (FOUCAULT,1987). A relativa novidade é que hoje ela conclama o público não apenas como uma massa espectadores que se rejubila com as emoções de cadafalso, mas como participantes ativos na busca e no uso individualizado de informações sobre criminosos.

Alguns projetos são colaborativos e contam com a produção direta de informações por parte dos usuários, tal como nos dois mapas de crime hoje 
on-line no Brasil. 0 Wikicrimes ${ }^{11}$, cujo slogan é "Compartilhe informações sobre crimes. Saiba onde não é seguro!", conclama os indivíduos a registrarem crimes segundo tipo, data, hora, local e se foi ou não informado à polícia. Há ainda a opção de adicionar uma descrição da ocorrência. 0 Citix restringe-se à cidade do Recife e sua sessão de "segurança e prevenção de crimes" conta com a colaboração dos usuários no registro e relato de crimes, com descrições mais ou menos detalhadas sobre 0 incidente. 0 espírito é montar um mapa de crimes a partir de relatos de experiências pessoais que sirvam de alerta quanto a zonas perigosas ou de denúncia da ineficiência da segurança pública. Um exemplo de relato:

Atenção todos que trabalham na Barbosa Lima e proximidades! Hoje, por volta das 7 h20 da manhã, um funcionário do $\mathrm{Cln}$ [sic] foi abordado por dois homens armados, em uma moto azul, que levaram seus pertences. Esses mesmos homens vêm praticando assaltos nas proximidades há alguns dias, nos horários da manhã e da noite, em motos de cores diferentes a cada dia. (Citix)

No blog do projeto, a perspectiva participativa, 0 uso personalizado da vigilância e a privatização da segurança são evidentes. Entretanto, este projeto se diferencia dos demais, pois não é apenas um dispositivo de vigilância distribuída para uso personalizado, mas integra uma rede de informações e ações coletivas em outros setores, como infra-estrutura, instituições, serviços públicos e entretenimento.

\section{Distribuição, naturalização e participação}

Thanks for a nation of finks. William Burroughs

Essas cartografias do crime revelam e põem em prática aspectos decisivos da atual vigilância distribuída e participativa, como se pôde notar. É certo que esse gênero de vigilância não é inédito. Ele continua e amplifica, sob meios e formas novas, antigas funções normativas do olhar social e comunitário, ou as mais recentes formas de "neighborhood watch" e "watchdogs". Apreender a sua especificidade atual requer explicitar seus nexos com pelo menos dois processos contemporâneos.

0 primeiro é a progressiva naturalização da vigilância como forma de observação, atenção e cuidado, incorporando-se ao repertório social, tecnológico, subjetivo e estético contemporâneo. A vigilância passa a se legitimar em diversos domínios, deixando de ter seu sentido vinculado a contextos específicos de controle, inspeção ou conhecimento. No seio desse cenário, produz-se uma indiscernibilidade entre vigias e vigiados, que, no limite, transforma todos em vigilantes e/ ou suspeitos potenciais. As atuais cartografias do crime reforçam tanto a naturalização da vigilância quanto essa indiscernibilidade, 0 que, por si só, já é extremamente problemático, uma vez que implicam uma relação com 0 outro mediada sobretudo pelo medo e pela suspeita. 
Ainda mais problemática é a associação dessa postura vigilante-policial à cidadania, presente no cruzamento da vigilância e da participação, segundo processo a ser levado em conta.

Como já se apontou, vigilância e participação se cruzam ao menos de dois grandes modos na cibercultura: nos recursos que as diversas formas de participação proveem à vigilância digital (BRUNO, 2008) na transformação do usuárioprodutor em vigilante. Os mapas de crime fazem parte desse segundo grupo, que conta com muitos outros casos. Vemos crescer, em diversos setores, uma série de proposições - tecnológicas, estéticas, discursivas, administrativas - que incitam os indivíduos a exercerem um olhar e uma atenção vigilantes sobre a cidade, 0 outro, o mundo. Um primeiro exemplo vem de uma vertente do jornalismo "cidadão" e "participativo", que convoca os indivíduos a flagrarem cenas de suposto interesse público e enviarem aos jornais as imagens disparadas por suas câmeras amadoras. A incitação a um olhar policial-jornalístico, associado a uma atitude "cidadã", é explícita em diversas campanhas do jornalismo participativo, sobretudo o da grande mídia.

Na televisão, programas que convocam a participação direta dos espectadores na captura de criminosos já não são novidade. A inovação fica ao encargo dos reality shows, que reproduzem aparatos policiais por meio dos quais os participantes são eliminados ou não, muitas vezes segundo o voto dos espectadores, os quais são convidados a assumirem uma posição entre 0 voyeur e 0 juiz-policial. No filão do entretenimento vigilante, cresce a presença dos departamentos de polícia nos ambientes midiáticos, sobretudo na Internet, incitando os cidadãos a assistirem as suas operações e a colaborarem no combate ao crime. Ampliamse, também, os serviços de vigilância lateral ou peer-to-peer, oferecendo meios de se vigiar familiares, colegas, empregados ou qualquer um, reproduzindo métodos policiais de inspeção misturados a demonstrações bem intencionadas de cuidado e proteção consigo e/ou com entes queridos. Paralelamente à vigilância multilateral e consentida das redes sociais, microblogs e outros serviços que dizem desde 0 que estamos fazendo até onde estamos, com maior ou menor riqueza de detalhes (e veracidade, pois sempre é possível dissimular), ampliam-se instrumentos que envolvem formas unilaterais e opacas de vigilância do outro. Sites que fornecem checagem do histórico de indivíduos, softwares que permitem rastrear e-mails e navegações de outrem etc. tornam corriqueiras práticas de vigilância antes restritas a instâncias policiais, científicas ou administrativas. Lógica similar alimenta a proliferação de dispositivos de vigilância doméstica e familiar, que permitem a pais, maridos e esposas monitorarem via câmeras de vídeo-vigilância, celulares, GPS e outros gadgets o cotidiano de familiares, a rotina e a segurança de suas casas, 0 trabalho de seus empregados etc. 
Os exemplos mostram a articulação, em maior ou menor grau, entre vigilância e participação na cibercultura. 0 termo vigilância participativa foi pela primeira vez utilizado por Mark Poster (1990) para apontar que nas novas tecnologias de comunicação não seríamos apenas disciplinados à vigilância, mas à participação. Na ocasião, 0 impulso participativo ainda não havia se tornado um lugar comum. Hoje, o termo é retomado e há uma disputa quanto ao seu sentido e ao seu valor. Para alguns autores, a vigilância participativa deve ser positivada seja como forma de empoderamento dos indivíduos na construção das relações sociais e da sua subjetividade

(ALBRECHTSLUND, 2008), seja como constituição de uma sociedade transparente e constantemente testemunhada e registrada não pelos estados e grandes corporações, mas pelos próprios cidadãos (CASCIO, 2005). No primeiro caso, o termo é pensado sobretudo no âmbito das redes sociais e reproduz a retórica frágil e simplificada da publicidade 2.0 que, em síntese, propõe que a participação voluntária traz consigo e por si a democratização, o empoderamento dos indivíduos, a criatividade, a partilha e a colaboração na produção e organização de informações e conteúdos. Ora, tudo isso é plenamente possível e mesmo potencializado, mas não garantido pela participação, e tanto suas formas históricas quanto as atuais não deixam dúvida. Do mesmo modo, não é preciso maior esforço cognitivo para perceber as apropriações e capitalizações da participação em favor de processos sociais, econômicos e políticos que não rimam harmonicamente com os atributos mencionados. Ou melhor, esses mesmos atributos podem ser as próprias fontes das tecnologias de poder e controle, e o mundo contemporâneo - do marketing às diversas formas de governo - não nos poupa exemplos. Além disso, o argumento de Albrechtslund de que a vigilância participativa seria positiva porque voluntária, contrariamente ao panóptico, que implicaria uma pseudoparticipação, é uma equação tão simplória quanto equivocada. Nem 0 caráter voluntário torna a vigilância positiva (ele pode inclusive envolver relações de poder ainda mais contundentes), nem o modelo de poder e vigilância exercido no panóptico encontra sua eficácia em falsos engajamentos ou em mecanismos repressivos e negativos, mas em procedimentos positivos de produção da verdade e da subjetividade.

0 segundo argumento, de que a vigilância participativa pode construir um outro regime de observação, visibilidade e ação política efetuado não mais por grandes centros, mas por inúmeros indivíduos, ações e decisões locais, é mais consistente. Conforme Cascio (2005), "The participatory panopticon will be...a bottom-up version of the constantly watched society". Isso engendraria, segundo o autor, inversões dos olhares vigilantes tradicionais, constituindo modos mais democráticos e transparentes de política e sociedade, em que a sousveillance (MANN, 2003) prevaleceria. "For the sousveillance movement, if the question is 'who 
watches the watchmen?' the answer is'all of us"' (CASCIO, op. cit).

De fato, vemos crescer, sobretudo no âmbito do ativismo político e da arte, projetos que constroem regimes de observação e visibilidade produtores de deslocamentos efetivos nas vias convencionais de poder, controle e vigilância. Tais projetos são tão mais interessantes quanto mais criam modos de visão, atenção e cuidado consigo e com o outro que escapam à lógica da suspeição generalizada, da delação, da inspeção policial, da prevenção constante frente ao risco. Dos ativistas que procuram dar visibilidade a questões sociais que ficam à margem da agenda midiática ou governamental, às imagens sem dono que circulam na Internet trazendo à tona, por exemplo, os rituais de tortura a que as tropas americanas submetem os iraquianos ou as atrocidades dos recentes ataques israelenses ao povo palestino, aos projetos artísticos que desviando os dispositivos de vigilância de suas funções policiais, voyeurísticas ou de controle social, inventando outros sentidos estéticos, políticos, vitais, são inúmeros casos que, mesmo minoritários, apontam para as potencialidades da participação na cultura contemporânea e no campo da contra-vigilância. Entretanto, é preciso diferenciar tais ações, que usam táticas e dispositivos de vigilância para subverter sua lógica policial, ou seja, aquelas que usam a participação contra a vigilância, daquelas que, como os mapas de crime, e não sem ambiguidade, tornam a participação mais um instrumento de vigilância. É preciso, ainda, desconfiar do sonho da transparência bottom-up embutida na ideia do "panóptico participativo" (CASCIO, op.cit), cujo risco foi antevisto por Burroughs: "thanks for a nation of finks."

Nesse sentido, são fundamentais as perspectivas que definem e problematizam a vigilância participativa, apontando seus limites e vínculos com as tecnologias de controle, nos quais se reiteram de forma privatizada os procedimentos policiais-estatais. Segundo Andrejevic,

The participatory injunction of the interactive revolution extends monitoring techniques... from Law enforcement and espionage to dating, parenting, and social life. In an era in which everyone is to be considered potentially suspect, we are invited to become spies - for our own good (op.cit, p. 240).

Os atuais movimentos de participação e colaboração são alvo de uma série de embates, dada a sua potencialidade na abertura de novas formas de fazer política, arte, conhecimento e cultura. Não por acaso, é exatamente aí que investem as próprias vias do controle, procurando capitalizá-los em seu favor. Identificar e problematizar as relações entre vigilância $\mathrm{e}$ participação é fundamental para desviar esse potencial do destino policial que lhe reserva uma das faces do impulso participativo na cibercultura.

\section{Referências}

ALBRECHTSLUND, Anders. Online social networking as participatory surveillance. First Monday, Chicago, vol. 13, n. 3, 2008. 
ANDREJEVIC, Mark. iSpy: surveillance and power in the interactive era. Lawrence: University Press of Kansas, 2007.

ANTOUN, Henrique. (org). Web 2.0: vigilância e participação na era da comunicação distribuída. Rio de Janeiro: Mauad, 2008.

BENTHAN, Jeremy. 0 Panóptico. Belo Horizonte: Autêntica, 2000.

BRUNO, Fernanda. Monitoramento, classificação e controle nos dispositivos de vigilância digital.

Famecos, Porto Alegre, n. 36, p. 10-16, 2008.

BUCI-GLUKSMAN, C. Loeil cartographique de l'art. Paris: Galilée,1996.

CASCIO, James. The rise of the participatory panopticon. WorldChanging, Seattle. Disponível em: $<$ http://www.worldchanging.com/archives/002651. html>. Acesso em: 04 maio 2005.

CRAMPTON, Jeremy. Cartographic rationality and the politics of geo-surveillance and security. Cartography and Geographic Information Science, v. 30, n. 2, p.135-148, 2003.

FOUCAULT, Michel. Vigiar e punir. Petrópolis: Vozes, 1987.

GANDY, Oscar. The panoptic sort : a political economy of personal information. Boulder: Westview Press, 1993.

GARLAND, David. The culture of control. Chicago: University of Chicago Press, 2001.

KOSKELA, Hille. Cam era: the contemporary urban Panopticon. Surveillance \& Society, Newcastle, v. 1, n. 3, p. 292-313, 2003.

LEMOS, A. Carnet de notes. Disponível em: <http:// www.andrelemos.info>. Acesso em: 06 ago. 2008.

MANN, Steve.; NOLAN, Jason.; WELLMAN, Barry. Sousveillance: inventing and using wearable computing devices for data collection in surveillance environments", Surveillance \& Society, Newcastle, v. 1, n. 3, p. 331-355, 2003.

MERLEAU-PONTY, Maurice. Fenomenologia da percepção. São Paulo: Martins Fontes, 1994.

ORWELL, George. 1984. São Paulo: Nacional, 2003.

POSTER, Mark. The mode of information. Chicago: University of Chicago Press, 1990.

SHORT, John Rennie. The world through maps.

Firefly Books, 2003.

TAYLOR, David Ruxton Fraser; CAQUARD, Sébastien. (eds.). Special issue of cartographica on Cybercartography, Toronto, vol. 41, n.1, 2006.

VAZ, Paulo. et alli. A vítima virtual e sua alteridade. Famecos, Porto Alegre, n. 30, p. 71-80, 2006. 


\section{Crime maps: distributed surveillance and participation in cyberculture}

\section{Abstract}

Under the participatory impulse in cyberculture, individuals are being encouraged to participate not only in entertainment and the production of goods and services, but also in the practices of surveillance. This article identifies and problematizes the relation between participation and surveillance in cyberculture through the concept of distributed surveillance, focusing on the latest available crime maps on the Internet.

\section{Keywords}

Surveillance. Participation. Crime maps.

Cyberculture.

\section{Mapas de la delincuencia: la vigilancia distribuida y la participación en la cibercultura}

\section{Resumen}

En el marco del impulso de la participación en la cibercultura, los individuos están siendo alentados a participar no sólo en las formas de entretenimiento y en la producción de bienes y servicios, sino también en la práctica de la vigilancia. Este artículo identifica y problematiza la relación entre la participación y la vigilancia de la cibercultura según el concepto de la vigilancia distribuida, centrándose en mapas de la delincuencia disponibles en Internet.

\section{Palabras clave}

Vigilancia. Participación. Mapas de la delincuencia. Cibercultura. 


\section{Expediente}

A revista E-Compós é a publicação científica em formato eletrônico da Associação Nacional dos Programas de Pós-Graduação em Comunicação (Compós). Lançada em 2004, tem como principal finalidade difundir a produção acadêmica de pesquisadores da área de Comunicação, inseridos em instituições do Brasil e do exterior.
E-COMPÓS I www.e-compos.org.br I E-ISSN 1808-2599

Revista da Associação Nacional dos Programas de Pós-Graduação em Comunicação. Brasília, v.12, n.2, maio/ago. 2009

A identificação das edições, a partir de 2008 passa a ser volume anual com três números.

\section{CONSELHO EDITORIAL}

\section{Afonso Albuquerque}

Universidade Federal Fluminense, Brasil

Alberto Carlos Augusto Klein

Universidade Estadual de Londrina, Brasi

Alex Fernando Teixeira Primo

Universidade Federal do Rio Grande do Sul, Brasi

\section{Alfredo Vizeu}

Universidade Federal de Pernambuco, Brasil

Ana Carolina Damboriarena Escosteguy

Pontifícia Universidade Católica do Rio Grande do Sul, Bras

Ana Silvia Lopes Davi Médola

Universidade Estadual Paulista, Brasil

André Luiz Martins Lemos

Universidade Federal da Bahia, Brasil

Ângela Freire Prysthon

Universidade Federal de Pernambuco, Brasil

Antônio Fausto Neto

Universidade do Vale do Rio dos Sinos, Brasil

Antonio Carlos Hohlfeldt

Pontifícia Universidade Católica do Rio Grande do Sul, Brasil

Arlindo Ribeiro Machado

Universidade de São Paulo, Brasil

César Geraldo Guimarães

Universidade Federal de Minas Gerais, Brasil

Cristiane Freitas Gutfreind

Pontifícia Universidade Católica do Rio Grande do Sul, Brasil

Denilson Lopes

Universidade Federal do Rio de Janeiro, Brasil

Eduardo Peñuela Cañizal

Universidade Paulista, Brasi

Erick Felinto de Oliveira

Universidade do Estado do Rio de Janeiro, Brasil

Francisco Menezes Martins

Universidade Tuiuti do Paraná, Brasil

Gelson Santana

Universidade Anhembi/Morumbi, Brasi

Hector Ospina

Universidad de Manizales, Colômbia

leda Tucherman

Universidade Federal do Rio de Janeiro, Brasil

Itania Maria Mota Gomes

Universidade Federal da Bahia, Brasil

Janice Caiafa

Universidade Federal do Rio de Janeiro, Brasil

Jeder Silveira Janotti Junior

Universidade Federal da Bahia, Brasil

\section{João Freire Filho}

Universidade Federal do Rio de Janeiro, Brasil

John DH Downing

University of Texas at Austin, Estados Unidos

José Luiz Aidar Prado

Pontifícia Universidade Católica de São Paulo, Brasil

José Luiz Warren Jardim Gomes Braga

Universidade do Vale do Rio dos Sinos, Brasil

Juremir Machado da Silva

Pontifícia Universidade Católica do Rio Grande do Sul, Brasil

Lorraine Leu

University of Bristol, Grã-Bretanha

Luiz Claudio Martino

Universidade de Brasília, Brasil

Maria Immacolata Vassallo de Lopes

Universidade de São Paulo, Brasil

Maria Lucia Santaella

Pontifícia Universidade Católica de São Paulo, Brasil

Mauro Pereira Porto

Tulane University, Estados Unidos

Muniz Sodre de Araujo Cabral

Universidade Federal do Rio de Janeiro, Brasil

Nilda Aparecida Jacks

Universidade Federal do Rio Grande do Sul, Brasil

Paulo Roberto Gibaldi Vaz

Universidade Federal do Rio de Janeiro, Brasil

Renato Cordeiro Gomes

Pontifícia Universidade Católica do Rio de Janeiro, Brasil

Ronaldo George Hela

Universidade do Estado do Rio de Janeiro, Brasil

Rosana de Lima Soares

Universidade de São Paulo, Brasil

Rossana Reguillo

Instituto Tecnológico y de Estudios Superiores do Occidente, México

Rousiley Celi Moreira Maia

Universidade Federal de Minas Gerais, Brasil

Sebastião Carlos de Morais Squirra

Universidade Metodista de São Paulo, Brasil

Simone Maria Andrade Pereira de Sá

Universidade Federal Fluminense, Brasil

Suzete Venturelli

Universidade de Brasília, Brasil

Valério Cruz Brittos

Universidade do Vale do Rio dos Sinos, Brasil

Veneza Mayora Ronsini

Universidade Federal de Santa Maria, Brasil

Vera Regina Veiga França

Universidade Federal de Minas Gerais, Brasil
COMISSÃO EDITORIAL

Ana Gruszynski I Universidade Federal do Rio Grande do Sul, Brasil Felipe da Costa Trotta I Universidade Federal de Pernambuco, Brasil Rose Melo Rocha I Escola Superior de Propaganda e Marketing, Brasil

\section{CONSULTORES AD HOC}

Aníbal Francisco Alves Bragança I Universidade Federal Fluminense, Brasil Benjamim Picado I Universidade Federal da Bahia, Brasil

Carlos Eduardo Franciscato I Universidade Federal de Sergipe, Brasi

Christa Liselote Berger I Universidade Vale do Rio dos Sinos, Brasil

Gisela Castro I Escola Superior de Propaganda e Marketing, Brasil

Luciana Pellin Mielniczuk I Universidade Federal de Santa Maria, Brasi

Marcia Benetti I Universidade Federal do Rio Grande do Sul, Brasil

Paulo Cunha Carneiro Filho I Universidade Federal de Pernambuco, Brasil

Raquel Recuero I Universidade Católica de Pelotas, Brasil

REVISÃO DE TEXTO E TRADUÇÃO I Everton Cardoso

EDITORAÇÃO ELETRÔNICA I Raquel Castedo
COMPÓS I www.compos.org.br

Associação Nacional dos Programas de Pós-Graduação em Comunicação

Presidente

Itania Maria Mota Gomes

Universidade Federal da Bahia, Brasil

itania@ufba.br

Vice-presidente

Julio Pinto

Pontifícia Universidade Católica de Minas Gerais, Brasil

juliopinto@pucminas.br

Secretária-Geral

Ana Carolina Escosteguy

Pontifícia Universidade Católica do Rio Grande do Sul, Brasil

carolad@pucrs.br 